\title{
The effect of preoperative anxiety and depression on postoperative pain and analgesic consumption in breast cancer surgery
}

\author{
S. M. Ismail1', M. Thomas' ${ }^{2}$, F. A. Philip ${ }^{3}$ \\ ${ }^{1}$ Resident, Regional Cancer Centre - Trivandrum (India), ${ }^{2}$ Additional Professor, Regional Cancer \\ Centre - Trivandrum (India), ${ }^{3}$ Assistant Professor, Regional Cancer Centre - Trivandrum (India)
}

\section{BACKGROUND AND GOAL OF STUDY}

Cancer patients with preoperative anxiety and depression can have more intense postoperative pain .The aim of this study was to investigate the relationship between the level of their anxiety and depression in the preoperative period and the pain level in the postoperative period and analgesic requirement, in a sample of Indian patients.

\section{MATERIALS AND METHODS}

After obtaining institutional review board and ethical committee approval this prospective study was conducted in 200 elective surgical adult female patients with carcinoma breast. Patients with psychiatric illness were excluded. Anxiety and depression were assessed preoperatively with generalised anxiety disorder (GAD-7) and patient health questionnaire (PHQ-9). All patients underwent surgery under standardised general anaesthesia. Post operative pain was assessed by numerical rating scale for $24 \mathrm{hrs}$. Post-operative analgesia was addressed with fentanyl and diclofenac

\section{RESULTS AND DISCUSSION}

Age, duration of surgery and socioeconomic status didn't affect postoperative pain. In the study population $13 \%$ had anxiety alone (A), 9.5\% of patents depression alone (D), $61 \%$ had both (B) and 16.5\% had neither (N). Patients who had anxiety as well as combined anxiety-depression had significantly higher pain scores compared to patients with no anxiety $(p<0.001)$. Average fentanyl use was $91 \mu \mathrm{g}$ in $(A), 65 \mu \mathrm{g}$ in (D), $118 \mu \mathrm{g}$ in (B) and $57 \mu \mathrm{g}$ in (N). Fentanyl use was significantly higher in $(A)$ and $(B)$ compared to $(N)(p<0.001)$. Average diclofenac use was $81 \mathrm{mg}$ in $(A), 55 \mathrm{mg}$ in $(D)$, $106 \mathrm{mg}$ in $(B)$ and $34 \mathrm{mg}$ in $(N)$. Diclofenac use was significantly higher in $(A)$ and $(B)$ compared to $(N)(p<0.001)$.

Depression and anxiety had significant correlation as $82 \%$ of patients with depression had anxiety. In patients with no depression, $63.5 \%$ of them did not have associated anxiety $(p<0.001)$. Correlating anxiety scores (GAD-7) anxiety had high positive correlation with depression with $r=0.605(p<0.001)$ and pain scores with $r=0.607(p<0.001)$.

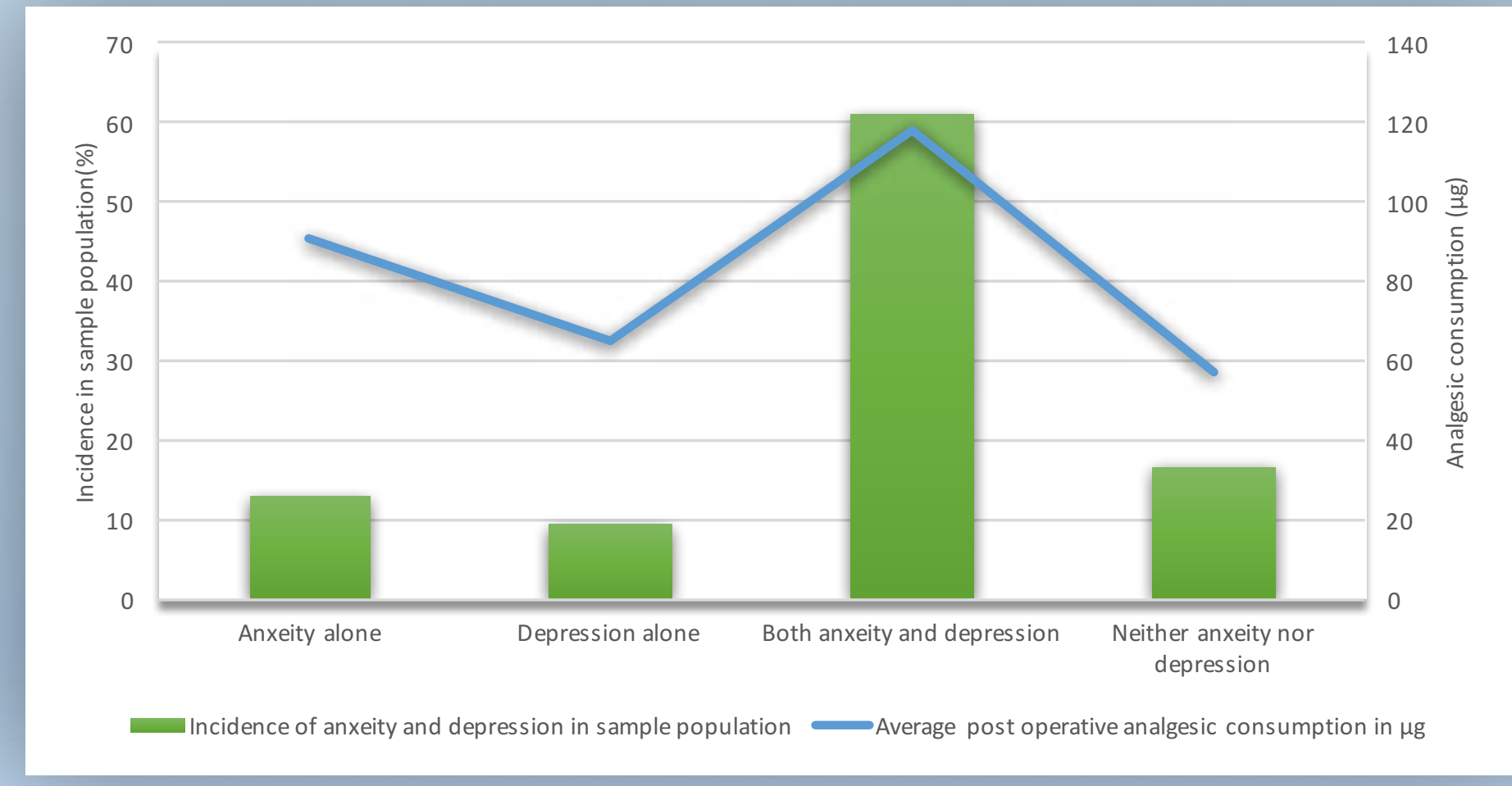

FIGURE 1: DISTRIBUTION OF ANXEITY AND DEPRESSION AMONG THE SAMPLE POPULATION VS POST OPERATIVE ANALGESIC CONSUMPTION

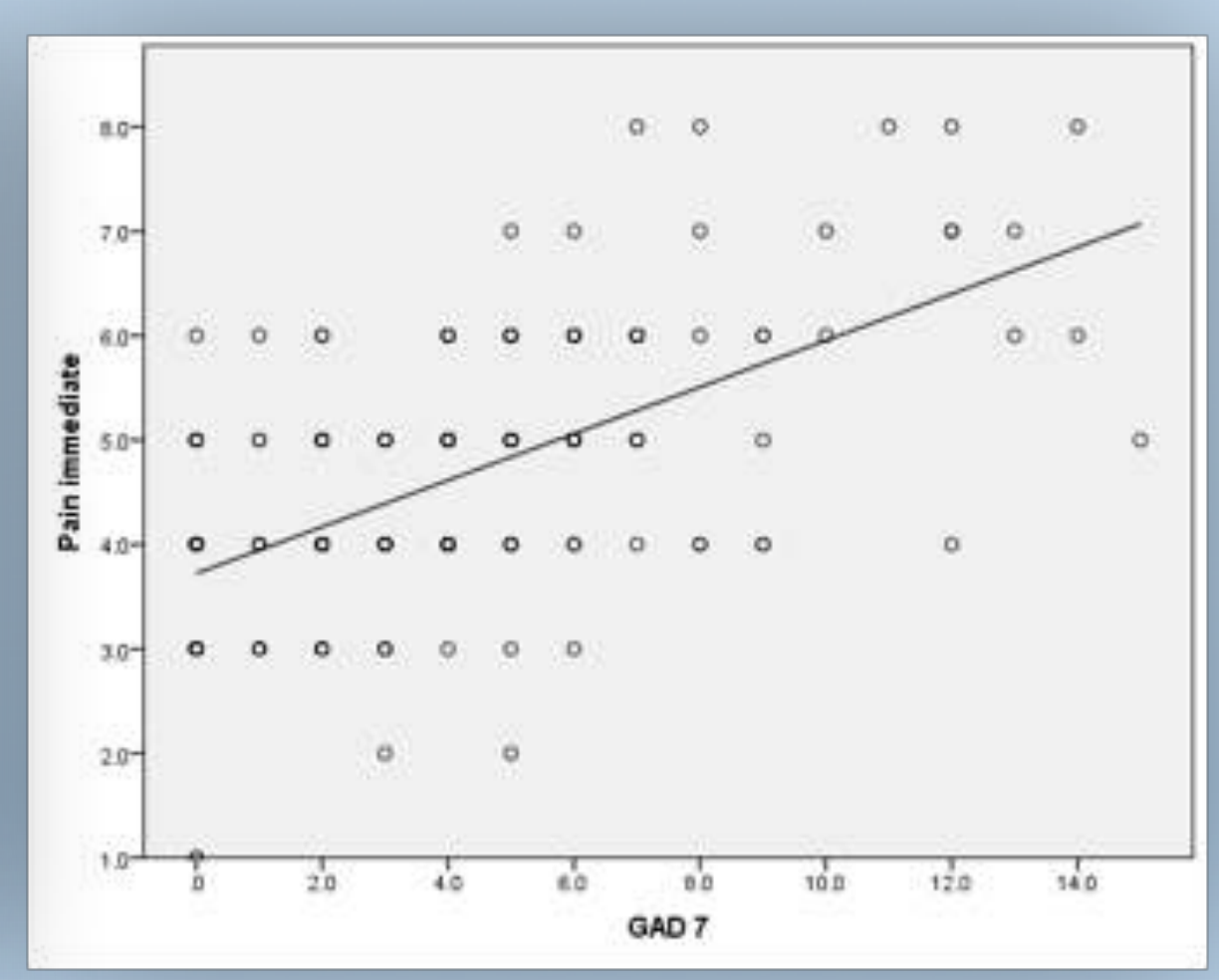

FIGURE 2: CORRELATION BETWEEN PAIN AND ANXEITY SCORES

\section{CONCLUSION(S)}

There is a high incidence of anxiety and depression in patients scheduled for breast cancer surgery and they are independent risk factors of post-operative pain and analgesic consumption.

Majority of these patients presented with combined anxiety-depression which resulted in increased pain and analgesic use. Therefore preoperative anxiolytics and antidepressants may reduce postoperative opioid requirement and may reduce cancer recurrence. 